Cayton, H. R. \& Preston, N. W. (1955). J. gen. Microbiol. 12, 519-525

\title{
Spirillum mancuniense n.sp.
}

\author{
By H. R. CAYTON* and N. W. PRESTON \\ Department of Bacteriology, University of Manchester
}

SUMMARY: A new species of Spirillum has been isolated from grass cuttings. Main characters : vacuoles and volutin granules; motile by lophotrichous or amphitrichous flagella; no spores; Gram-negative; good growth in 0.5 \% Evans peptone; no growth in meat extract or grass infusion ; inhibited by $0.5 \%(\mathrm{w} / \mathrm{v})$ sodium chloride ; catalasenegative; microaerophilic; good growth at $4^{\circ}$; optimum temperature $28^{\circ}$. The species has been designated Spirillum mancuniense.

An infusion of grass cuttings from a compost heap was found to contain a short spirillum. Although the organism was grossly out-numbered by other organisms, it was particularly striking on account of its active motility which was maintained for several days. The experimental results recorded here are the outcome of an attempt to isolate this organism in pure culture.

\section{The isolation of the organism}

Initial isolation in pure culture. The first step in the isolation of the spirillum in pure culture was the search for a solid medium on which it would grow. As nutrient agar was unsuccessful an attempt was made to simulate the cultural conditions under which the organism had already grown. A medium was prepared consisting of an autoclaved mixture of the compost infusion described above, hay infusion, and water from a bucket which had been standing out-ofdoors for several weeks, the whole being solidified with $2 \%(w / v)$ agar. After incubation for 2 days at $23^{\circ}$, a stained film of the confluent growth revealed a sufficiently large proportion of spirilla to suggest that multiplication of this organism had occurred; but films made from numerous isolated colonies consisted only of cocci, bacilli and fungi. However, by examining the culture under the 16 and $4 \mathrm{~mm}$. objectives of a microscope, growth of the spirillum could be detected. (Pl. 1, figs. 1 and 2, shows the microscopic appearance of spirillum colonies in pure culture as finally obtained.) Prolonged search of several plates revealed a spirillum colony which was sufficiently isolated ( $\mathrm{Pl}$. 1, fig. 3) to enable a pure subculture to be made.

Repeated subculture in reproducible medium. The initial isolation in pure culture from a colony was made in filtered autoclaved water from a bucket which had been standing out-of-doors for several weeks, this medium being used quite empirically for no better reason than its previous use as a component of a successful solid medium. However, it obviously lacked reproducibility, and moreover the growth gradually became less and less profuse and eventually ceased after 43 subcultures, even when large inocula were used. Meanwhile

\footnotetext{
* Present address: The Department of Preventive Medicine, University of Bristol.
} 
various combinations of Yeastrel, hay infusion and grass infusion were tried. These were either unable to support growth at all, or were adequate for not more than three subcultures. The organism would not grow in standard laboratory media such as nutrient broth, digest broth, glucose broth, peptone water (containing sodium chloride), or Koser's citrate. It still thrived, however, after 100 subcultures in a solution of $0.5 \%(\mathrm{w} / \mathrm{v})$ peptone (Evans) in distilled water, the reaction being adjusted to $\mathrm{pH} 7 \cdot 5$ before sterilization in the autoclave. Oxoid peptone gave equally good growth, as indicated by three subcultures, but cultures in Difco Bactopeptone and Witte peptone were less turbid.

\section{Description of the organism}

Morphology. The size of the organism in $0.5 \%$ Evans peptone was as follows: diameter $0.7-1 \cdot 0 \mu$. (most were about $0.9 \mu$.), wavelength $(\lambda) 7-8 \mu$., spiral width $2-3 \mu$. The average length was about $7-8 \mu$. $(=\lambda)$; many were short vibrio forms $(\lambda / 4)$, but lengths of $2 \lambda$ and $3 \lambda$ were common, and occasionally the spirillum reached a length of $30-40 \lambda$ or more (Pl. 2, figs. 4, 5). Most of the organisms in young cultures stained uniformly with simple stains such as methylene blue (Pl. 2, fig. 6), but as the cultures aged some of the organisms went through a series of changes in their internal structure. After incubation for 1 day at $28^{\circ}$, some organisms developed a series of vacuoles along their length. Pl. 2, fig. 7, shows an unusually high proportion of organisms of this type. After 10 days, very few vacuoles were left, but many organisms had developed a number of granules with a distribution similar to that of the vacuoles seen in younger cultures (Pl. 2, fig. 8). Both the granules and the few remaining vacuoles were beginning to cause slight bulging of the spirillum. By the 24th day, many organisms had been grossly distorted by swollen granules, many of which had coalesced to form short fat curved bodies which stained intensely (Pl. 2, fig. 9). Some of these swollen granules had become almost globular (Pl. 2, fig. 10); occasional organisms contained unstained vacuoles of a similar size. Pl. 2, fig. 11, shows two organisms which contain large pale structures intermediate between the unstained vacuoles and the deeply stained granules. There was little change in the appearance of cultures during the next few weeks, but by the 15th week the organisms consisted of short spiral forms (which had been present at all stages) and ill-defined poorly staining globular forms (Pl. 2, fig. 12). No granules were seen at this stage.

Electron microscopy. Suspensions of young cultures grown on 0.5\% Evans peptone solidified with $2 \%(\mathrm{w} / \mathrm{v}$ ) Oxoid agar (New Zealand, L 10) were examined by the electron microscope, using electron-accelerating voltages of 25 and $75 \mathrm{kV}$. The former voltage revealed tufts of flagella at one or both poles (Pl. 2, fig. 13) whilst the internal structure was poorly differentiated. At $75 \mathrm{kV}$. the flagella were less distinct, but the cytoplasm was seen to contain well-defined dense bodies and also some ill-defined areas which had but little deflecting effect on this faster electron beam (Pl. 2, fig. 14). The relation between these internal structures and the vacuoles and granules seen in stained films is discussed later. 
Staining. The best contrast between granules and cytoplasm was obtained by staining heat-fixed films with Mayer's haemalum for 5 min. With this method, the granules appeared as sharply demarcated violet areas in a pale purple cytoplasm. Polychrome methylene blue stained the granules purple and the cytoplasm blue, but the intensities of the two colours were more nearly equal and, in consequence, the contrast between granules and cytoplasm was less marked. With Neisser's method, the granules stained black and the cytoplasm brownish yellow, but the granules absorbed so much stain that they lacked definition. Neither the granules nor the vacuoles gave positive staining reactions for spores (Moeller's method), fat (Sudan IV, and Sudan Black B), or sulphur (sodium nitroprusside). Films made from overnight cultures stained uniformly Gram-negative.

Cultural characters. The only medium in which the organism was found to grow profusely in repeated subculture was $0.5 \%$ Evans peptone. Sodium chloride was inhibitory even in low concentrations (Table 1). Other anions and cations showed similar or more marked degrees of inhibition (Table 2).

Table 1. Growth of spirillum in presence of sodium chloride, using $0.5 \%$ Evans peptone as basal medium

$\begin{array}{ccl}\begin{array}{c}\text { Concentration of } \\ \text { sodium chloride } \\ \%(w / v)\end{array} & \text { Growth } & \text { Motility } \\ 0 & +++ & \text { Active } \\ 0.2 & +++ & \text { Active } \\ 0.3 & ++ & \text { Active } \\ \mathbf{0 . 4} & + & \text { Reduced } \\ \mathbf{0 . 5} & \pm & \text { Very sluggish } \\ \mathbf{0} \cdot 6 & \pm & \end{array}$

Nutrient broth did not support growth; omission of sodium chloride from this medium gave no improvement. A simple meat extract (i.e. nutrient broth from which both salt and peptone had been omitted) gave a slight growth on primary subculture but subsequent subculture in the same medium was unsuccessful. On potato, the growth was very scanty and greyish in colour. Gelatin $(5 \%, \mathrm{w} / \mathrm{v})$ stab cultures liquefied very slowly, the maximum growth occurring about $5 \mathrm{~mm}$. below the surface. On a medium consisting of $0.5 \%$ Evans peptone solidified with $10 \%(\mathrm{w} / \mathrm{v})$ gelatin, the colonies were small (up to $1 \mathrm{~mm}$. in diam.) and greyish in colour.

Good growth was obtained on $0.5 \%$ Evans peptone solidified with $2 \%$ (w/v) Oxoid agar (New Zealand, L 10), the colonies reaching a size of 2-3 mm. diam. when grown aerobically for 3 days at $28^{\circ}$; under strictly anaerobic conditions the growth on this medium was less profuse. But a diminution of air pressure to $60 \mathrm{~mm}$. Hg resulted in slightly better growth than that obtained at atmospheric pressure. This preference for microaerophilic conditions was confirmed by the growth in gelatin stab cultures described above.

Temperature range. Liquid cultures were markedly turbid after overnight incubation at $28^{\circ}$, which was the optimum temperature. Below and above this temperature growth was less profuse, but the organism grew slowly even at $4^{\circ}$ 
At temperatures above $28^{\circ}$ the growth rate declined more rapidly than below $28^{\circ}$; at $36^{\circ}$ there was only a trace of growth and the organisms were non-motile. No growth occurred at $44^{\circ}$, and after 2 days at this temperature the organisms were dead.

The absence of heat-resistant spores, suggested by the above result, was confirmed by heating 10-day, 4-week, and 12-week cultures at $60^{\circ}$ for $30 \mathrm{~min}$. All three cultures were killed. The vegetative form of the organism, however, could itself survive for several weeks at room temperature; cultures were still viable after 10 weeks but not after 15 weeks.

Table 2. Relative growth of spirillum in presence of equivalent concentrations of various anions and cations, using $0.5 \%$ Evans peptone as basal medium

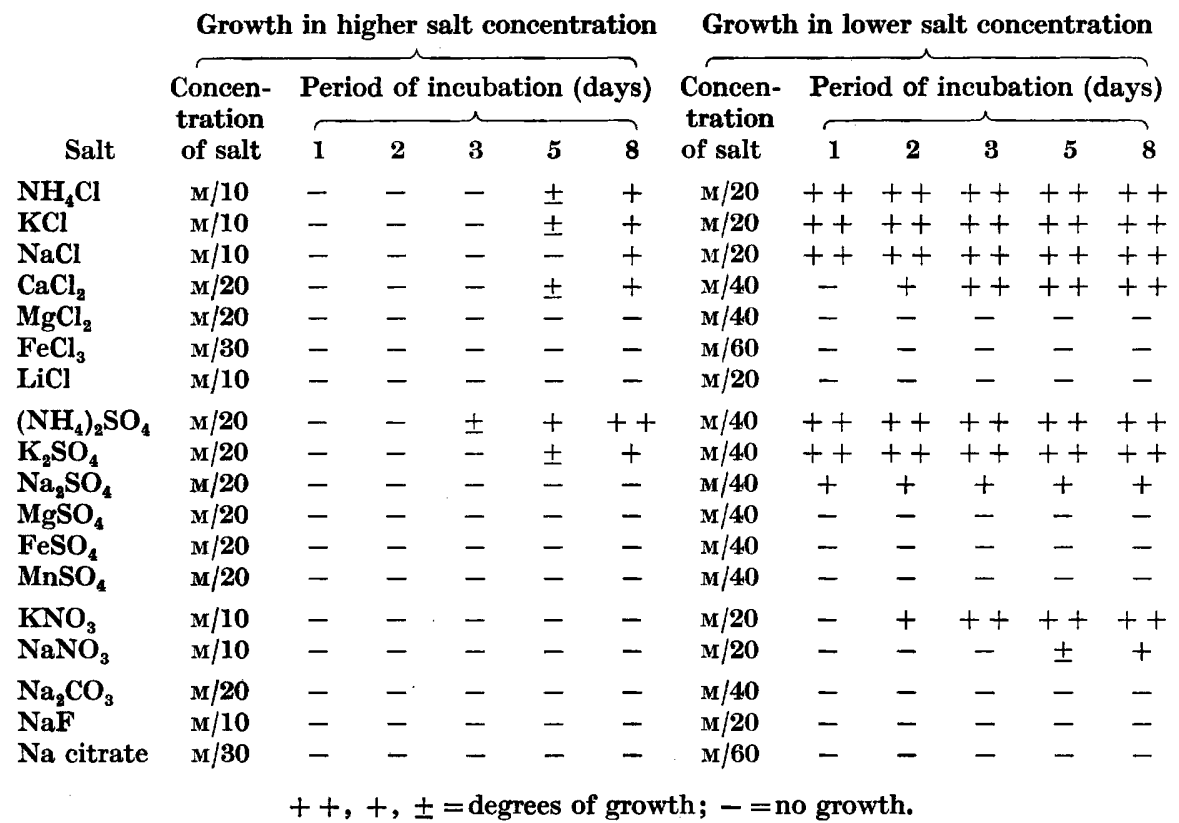

Biochemical reactions. Using $\mathbf{0 . 5} \%$ Evans peptone as the basal medium, it was found that the spirillum did not ferment glucose (22 days at $30^{\circ}$ ), did not produce indole, and did not reduce nitrate to nitrite. Catalase was not produced by growth on peptone agar.

Preservation. It was not possible to preserve the spirillum by freeze-drying in serum, and only a low survival rate was obtained with $7 \cdot 5 \%(\mathrm{w} / \mathrm{v})$ glucose as the suspending fluid. But more successful results were obtained with the Mist. desiccans of Fry (1951) using 0.5\% Evans peptone in place of nutrient broth. By this method, viable organisms were recovered from all ampoules opened within a week of freeze-drying in vacuo, but after storage for 4 months at room temperature there were no survivors.

The organism could be maintained by monthly subculture in $0.5 \%$ Evans peptone at $4^{\circ}$; this method was completely reliable. 
Pathogenicity. The spirillum was non-pathogenic to mice and guinea-pigs. These animals were still healthy 2 months after intraperitoneal injection with $0.5 \mathrm{ml}$. of a heavy suspension of the organism.

\section{DISCUSSION}

The classification of this organism does not present any great difficulties. Its general characters (spiral shape, presence of volutin granules, tufts of polar flagella, origin in decaying organic matter) place it in the genus Spirillum as described in Bergey's Manual (1948). It belongs to the subgroup of smaller organisms which develop volutin granules, but differs from previously described spirilla of similar size in several of its properties, the most striking of which are its inability to grow in broth, its very poor growth on potato, and the absence of catalase. These differences seem to justify species differentiation.

Although species of similar size to this new strain have been grown on several artificial media, some other spirilla have not been so cultivated. The organism described in this communication has grown well in repeated subcultures only in a simple solution of Evans peptone to which no salt was added. In fact, one of the peculiar features of this strain is its inhibition by sodium chloride in a concentration as low as $0.5 \%(w / v)$. Possibly this inhibition may apply more widely and may explain the recorded failures of other species to grow in artificial media. In this connexion the work of Kutscher (1895) and Giesberger (1936) is relevant. Spirillum kutscheri grew in 'Fleischwasser' but not in a peptone common salt solution (salt concentration not stated). Giesberger, likewise, did not define the 'Peptonwasser' and 'Peptonagar' which supported growth; the text implies the absence of added salt but there is nothing to show that common salt is inhibitory.

The literature is lacking in detailed morphological descriptions of spirilla, so that the interesting changes found in ageing cultures of this new species might apply to other species. Rows of vacuoles in very young cultures are mostly replaced, by the end of a week, with similar rows of volutin granules which subsequently increase enormously in size so that they grossly distort the former spiral shape of the cells. Occasionally, swollen vacuoles of a similar shape are seen; Pl. 2, fig. 11, shows two such vacuoles staining faintly with the same reaction as the more common swollen granules. These findings suggest that the granules develop from the vacuoles as the latter become filled with volutin material. No function has been ascribed to these swollen and globular forms of the organism, and they have not been shown to play any part in a 'life-cycle' of the spirillum. It would indeed be interesting to isolate cells of this type and determine whether they were capable of reversion to the original spiral shape. At present, however, they appear to be merely degeneration forms.

Electron micrographs of young cultures show small opaque bodies which occur in areas quite separate from the vacuoles. This may seem to refute the theory that vacuoles develop into volutin granules, but on the other hand there is no reason to suppose that an area which has a marked deflecting effect 
on a beam of electrons is necessarily the same as one which stains as a volutin granule. Further light may be thrown on this problem by electronmicrography of older cultures and comparison with stained preparations.

Although this organism has several properties not previously described amongst species of Spirillum, further investigations may reveal that one or more of these characters is common to other species. Moreover, some of these newly described properties may well be shared with species which have not yet been isolated. It therefore seems to be safer, in providing a name for the organism, to avoid a term which describes an individual morphological or physiological character. Accordingly, the new species has been designated Spirillum mancuniense.

\section{Main features of the new species}

Spirillum mancuniense n.sp. Spiral organism 0.7-1.0 $\mu$. in diam., wavelength 7-8 $\mu$., spiral width 2-3 $\mu$., length 2-300 $\mu$. Motile by tufts of polar flagella. Vacuoles and volutin granules. No spores, fat, or sulphur. Gram negative. Colonies on peptone-agar smooth, round, greyish, 2-3 mm. diam.

Microaerophilic, facultative aerobe and anaerobe. Optimum temperature $28^{\circ}$; good growth at $4^{\circ}$. Vigorous growth in $0.5 \%(w / v)$ Evans peptone. Very scanty growth on potato; no growth in meat extract or nutrient broth. Inhibited by $0.5 \%(w / v)$ sodium chloride. Slow liquefaction of gelatin. No fermentation of glucose. Indole not produced. Nitrate not reduced. Catalase negative. Non-pathogenic. Isolated at Manchester from decaying grass cuttings.

A subculture has been deposited in the National Collection of Type Cultures, Central Public Health Laboratory, Colindale Avenue, London, N.W. 9 (NCTC no. 9582).

The authors are indebted to Messrs Metropolitan-Vickers Ltd. for the electron micrographs.

\section{REFERENCES}

Bergey's Manual of Determinative Bacteriology (1948). 6th ed. Edited by Breed, R. S., Murray, E. G. D. and Hitchens, A. P. London: Baillière, Tindall and Cox. Fry, R. M. (1951). The influence of the suspending fluid on the survival of bacteria after drying. In Freezing and Drying, p.' 107. London: Institute of Biology.

Giesberger, G. (1936). Beiträge zur Kenntnis der Gattung Spirillum Ehbg. Thesis, Delft.

Kutscher (1895). Spirillum Undula minus und Spirillum Undula majus. Z. Bakt. (I. Abt.), 18, 614.

\section{EXPLANATION OF PLATES}

\section{Plate 1}

Photomicrographs of colonies of Spirillum mancuniense

Fig. 1. Pure cultures after 2 days at $23^{\circ}$. Colonies have undulating edge. $\times 200$.

Fig. 2. Same culture as fig. 1 , after 1 day at $23^{\circ}$. Shows how the spiral organisms produce the undulating edge seen with lower magnification in fig. $1 . \times 700$.

Fig. 3. Mixed culture showing one isolated colony of spirillum (arrowed). $\times 200$. 
Journal of General Microbiology, Vol. 12, No. 3
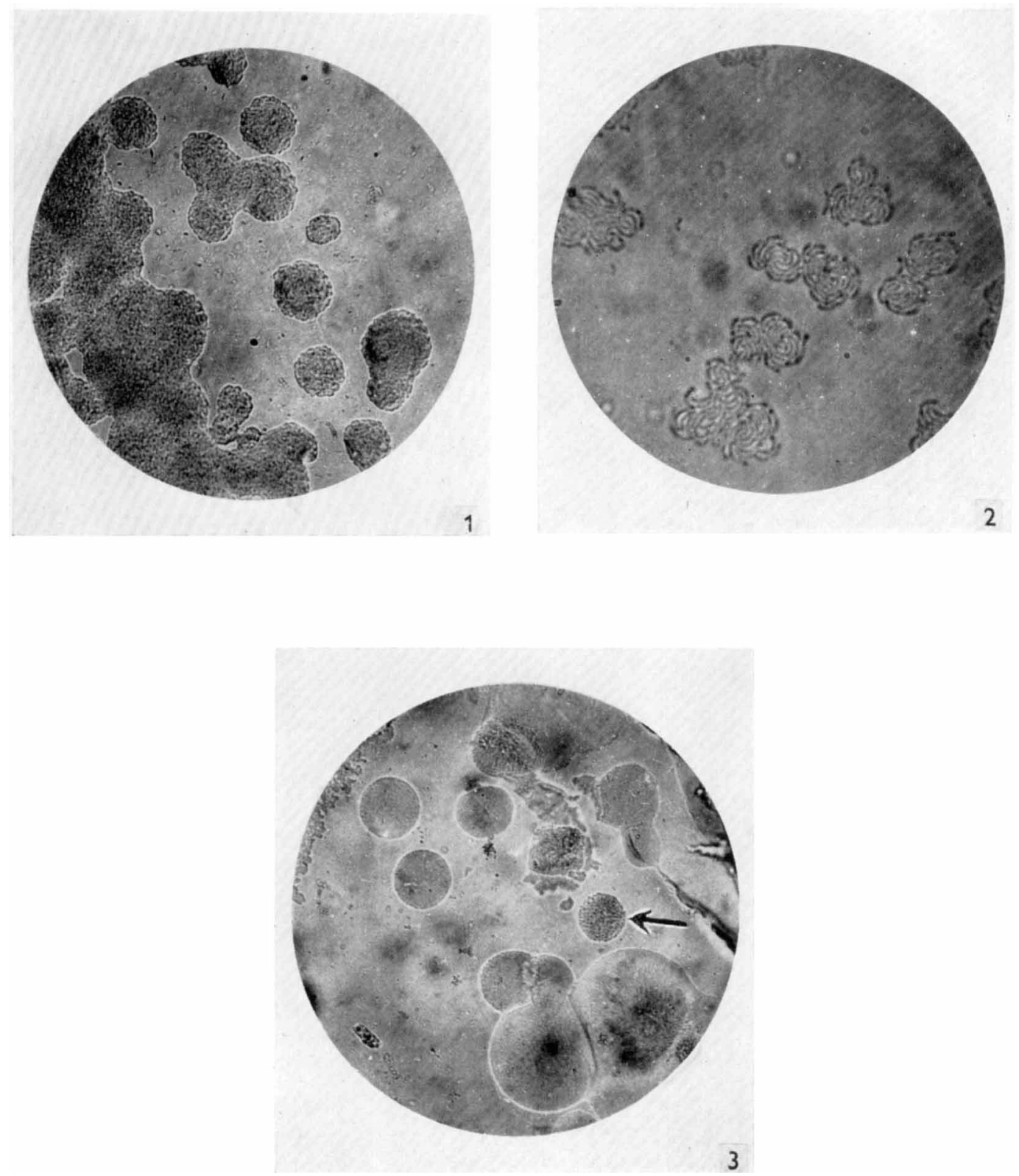

H. R. Cayton \& N. W. Preston-Spirlllum alancuniense n.sp. Platei 1 
Journal of General Microbiology, Vol. 12, No. 3

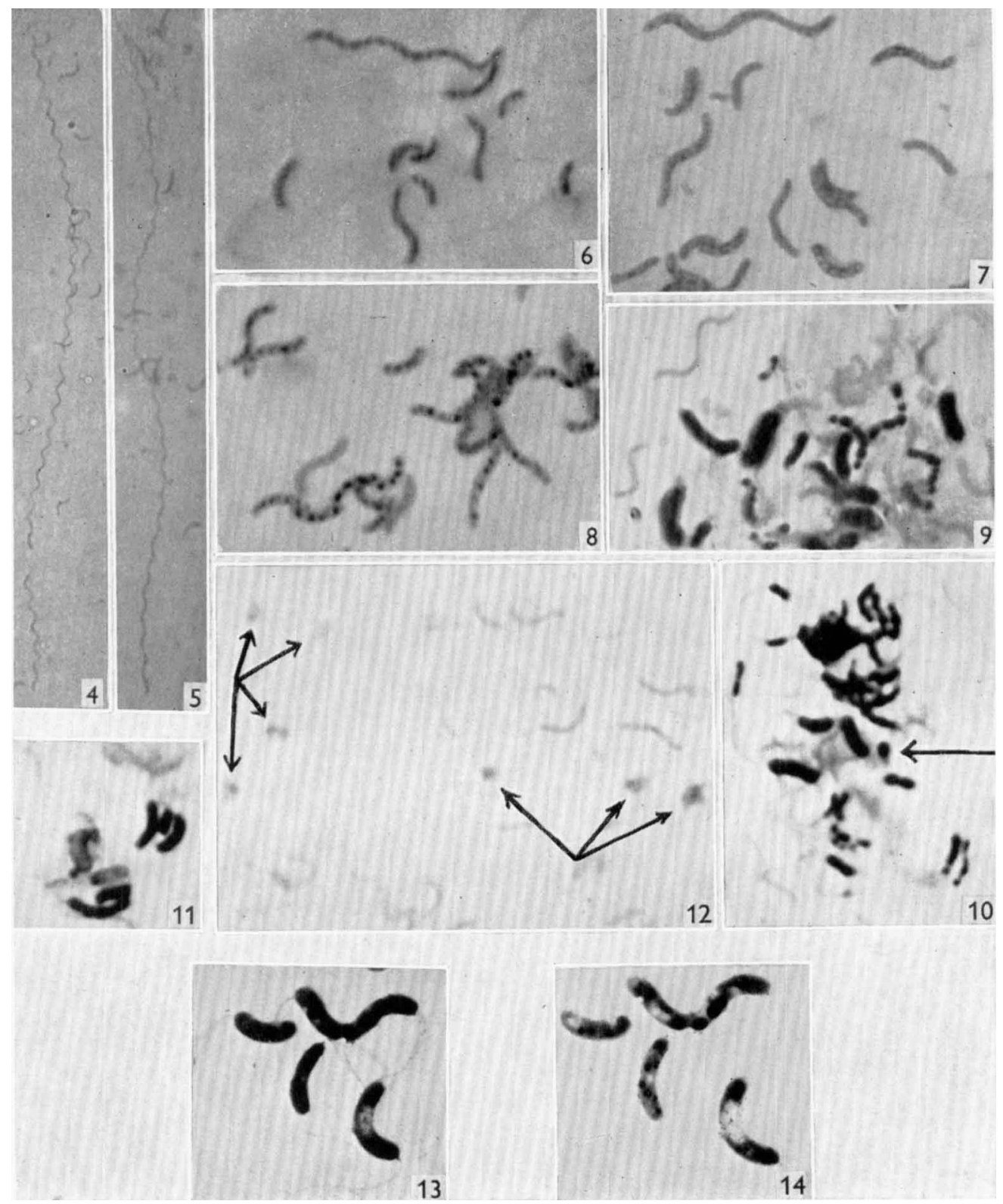

H. R. Cayton \& N. W. Preston-Spirillum Mancuniense n.Sp. Plate 2 


\section{Spirillum mancuniense $n . s p$.}

Plate 2

Photomicrographs of Spirillum mancuniense, stained with haemalum, after growth in $0.5 \%(w / v)$ Evans peptone at $28^{\circ}$

Fig. 4. An organism of about 30 wavelengths in a 2-day culture. $\times 375$.

Fig. 5. A similar spirillum seen in a 3-week culture. $\times 450$.

Fig. 6. A typical field, showing uniform staining of cells in a young culture (3-day). $\times 1200$.

Fig. 7. One-day culture. This field shows an unusually high proportion of cells with vacuoles. $\times 1350$.

Fig. 8. Ten-day culture. Vacuoles mostly replaced by volutin granules. $\times 1200$.

Fig. 9. Twenty-four-day culture. Cells becoming distorted as the granules swell and coalesce. $\times 1200$.

Fig. 10. Same as fig. 9. The arrow points to the final globular shape which the swollen granules assume. $\times 1200$.

Fig. 11. Same as fig. 9. Note the two cells with large pale granules, probably swollen vacuoles filling with volutin material. $\times 1200$.

Fig. 12. Fifteen-week culture. The globular granules have degenerated and are now illdefined. Spiral forms of the organism are present in this and all younger cultures. $\times 1200$.

Electron micrographs of suspension of Spirillum mancuniense from 3-day growth on $0.5 \%$ peptone solidified with agar.

Fig. 13. Electron-accelerating voltage of $25 \mathrm{kV}$. Tufts of polar flagella are seen, but the internal structure of the cells is ill-defined. $\times 2500$.

Fig. 14. Electron-accelerating voltage of $75 \mathrm{kV}$. Internal structure is revealed better, but flagella are indistinct. $\times \mathbf{2 5 0 0}$.

(Received 1 December 1954) 